\title{
Nature-Based Solutions in an Urban Perspective ${ }^{+}$
}

\author{
Johanna Sörensen \\ Department of Water Resources Engineering, Lund University, 22363 Lund, Sweden; \\ johanna.sorensen@tvrl.lth.se \\ † Presented at TERRAenVISION 2019, Barcelona, Spain, 2-7 September 2019. \\ Published: 28 October 2019
}

\begin{abstract}
The traditional engineering approach to manage urban drainage is by combined or separated sewers. In urban catchments, drainage systems may include different types of storage and detention facilities to avoid flooding from heavy rainfall. However, during recent decades, alternative ways to manage floods have evolved since traditional methods often harm the riverine ecosystems by pollution and erosion and increase the flood risk in the downstream extent of a catchment. Green spaces are important in urban areas for many different reasons: recreation, maintenance of biodiversity, city structure, cultural identity, environmental quality of the urban area, and as biological solutions to technical problems in urban areas. However, plans for urban green spaces often do not take into consideration the multiple purposes of green spaces and the relation between urban green spaces and water is only to a limited degree mentioned and discussed in such plans. Densification has become a dominating urban planning strategy, as many cities strive to reduce their negative, environmental impact. As a consequence of urban densification, the need for solid strategies to preserve, build, develop and ideally simultaneously increase the quantity (area) and quality of green and blue spaces (vegetation and surface water) in urban areas in a multifunctional manner increases. The combination of climate change adaptation, densification, pollution, the call for more green spaces, and a need to restore aging sewers, leads to strong interest in retrofitting of urban areas with nature-based solutions (NBS). Incorporation of NBS into decisionmaking and ways to handle integrative and multi-criteria aspects in the legal and organisational system are still to a great extent not done. The current regime for stormwater management, through piped drainage, is dominating and many cities face a lack of green spaces. Introducing more naturebased solutions is faced with barriers that are largely socio-institutional rather than technical. In this keynote session such barriers, as well as drivers, for wide-spread implementation of NBS, as well as data management strategies to help the implementation, are discussed. Based on transition theory, socio-technical transition towards wide-spread implementation of such measures were examined through interviews with municipal and water utility officials. Legal, organisational and financial changes are suggested. This keynote session also discusses urban, pluvial flooding and if NBS can be used as a strategy for resilient flood risk management. Spatial analyses of flood claims from insurance companies and the water utility company of Malmö are used to study how NBS impact flood risk.
\end{abstract}

Keywords: urban hydrology; pluvial flooding; water management

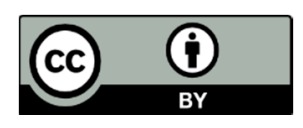

(C) 2019 by the authors. Licensee MDPI, Basel, Switzerland. This article is an open access article distributed under the terms and conditions of the Creative Commons Attribution (CC BY) license (http://creativecommons.org/licenses/by/4.0/). 